\title{
EFFECT OF THE STACKING SEQUENCE ON THE IMPACT RESPONSE OF CARBON-GLASS/EPOXY HYBRID COMPOSITES
}

\author{
Hafiz Tauqeer Ali ${ }^{1}$, Roya Akrami ${ }^{2}$, Sakineh Fotouhi ${ }^{3}$, \\ Farzad Pashmforoush ${ }^{4}$, Cristiano Fragassa ${ }^{5}$, Mohammad Fotouhi ${ }^{6}$ \\ ${ }^{1}$ Department of Mechanical Engineering, Taif University, Kingdom of Saudi Arabia \\ ${ }^{2}$ Your Engineered Structures LTD, Glasgow, United Kingdom \\ ${ }^{3}$ Department of Mechanical Engineering, University of Tabriz, Iran \\ ${ }^{4}$ Department of Mechanical Engineering, University of Maragheh, Iran \\ ${ }^{5}$ Department of Industrial Engineering, University of Bologna, Italy \\ ${ }^{6}$ School of Engineering, University of Glasgow, United Kingdom
}

\begin{abstract}
This paper investigates low-velocity impact response of Quasi Isotropic (QI) hybrid carbon/glass fiber reinforced polymer composites with alternate stacking sequences. Cross-ply woven carbon and glass fibers were used as reinforcing materials to fabricate sandwiched and interlayer hybrid composites. For comparison, the laminates containing only-carbon and only-glass fibers were also studied. Drop weight test was used to impact the samples. The images captured by a normal camera demonstrated that localized damages (delamination) existed within plies. The hybrid laminates had smaller load drops, smaller maximum deflection, and higher maximum load compared to the single fiber laminates. In addition, carbon outside interlayer hybrid laminate showed the highest maximum load and energy absorption, showing the significant dependence of the impact performance on hybridization and stacking sequence. It was concluded that a hybrid composite would help improve impact performance of laminated composites compared to non-hybrid composites if they are properly designed.
\end{abstract}

Key Words: Damage, Glass/Carbon Hybrids, Impact, Stacking Sequence

\section{INTRODUCTION}

Glass or carbon fiber reinforced polymer composites have been conveniently used in a large selection of industrial products and applications [1], as aerospace and aircrafts $[2,3]$, automotive [4-6], ships and sailing [7, 8], biomedicine and sports [9, 10].

Received November 19, 2019 / Accepted January 26, 2020

Corresponding author: Mohamad Fotouhi

School of Engineering, University of Glasgow, Glasgow G12 8QQ, United Kingdom

E-mail: Mohammad.Fotouhi@glasgow.ac.uk 
This is especially due to their high strength to weight ratio and non-corrosive properties. However, brittle failure and poor impact performance are two major drawbacks, which have led to the conservative design and large reserve factors in the design of these composite structures $[11,12]$.

Hybridization is one of the successful methods to achieve gradual failure or pseudoductility $[13,14]$. In this method, two types of plies with different fibers are co-cured to achieve a desired performance, and to produce a more cost-effective material $[15,16]$. Most of the work done to-date on hybrid composites has concerned hybrids under tensile [17, 18], bending and compression loadings [19-21]. There are also some studies on hybrid composites when subjected to indentation and impact loadings [22-28]. It was reported that for given materials, stacking sequence is a major factor governing the hybrid's behavior [29]. For example, carbon outside carbon/glass hybrid composites was reported to have the highest maximum load when subjected to impact [24, 25]. Different combinations of glass/carbon hybrids were studied under impact. They have concluded that increasing the percentage of glass fiber has a positive effect on absorbed energy and maximum load [30].

Despite the previous studies, the stacking sequence of hybrid structures becomes a key challenge on how to fully utilize the benefits of hybridization. Some of the common stacking sequences used in hybrid composites are intermingled continuous fibers [31], intermingled aligned short fibers [32], interlayer or sandwiched layers [33] and intralayer [34].

This project aims at experimentally investigating the low-velocity impact responses of varied interlayer carbon/glass hybrid configurations, due to the simplicity of the hybridization method in manufacturing. It was found that a hybrid composite would help improve impact performance of laminated composites compared to non-hybrid composites if they are designed in proper sequences.

\section{MATERIALS, MANUfACTURING AND TESTING}

A schematic of the investigated composites and their stacking sequence are shown in Fig. 1. Composites consist of Axiom 5180 carbon fiber/epoxy and Axiom 3180 glass fiber/epoxy, which are cross-ply woven prepregs commonly used for aerospace applications, and labeled in the figure as ' $C$ ' and ' $G$ ', respectively.

Those prepregs were laid up with different stacking sequences to achieve quasiisotropic mechanical properties, as detailed in Table 1, where the fiber orientation is specified for each layer (e.g. $0 / 90$ or \pm 45 ) and ' $s$ ' introduces the symmetry of sequences.

A cure of 90 minutes at $130{ }^{\circ} \mathrm{C}$ was performed for the investigated composite plates.

The plates were manufactured according to ASTM D7136 standards [35].

Current plates have dimensions of $300 \times 300 \mathrm{~mm}^{2}$. These were then cut into $100 \mathrm{~mm}^{2}$ test samples pieces. The pieces were cut in such a way that the laminates which have zero angles are oriented along the short edge direction of the test specimens. Fig. 2 illustrates the test rig, clamp and the set up. These were designed in accordance with ASTM standard D7136 [35]. Four rubber tipped toggle clamps were used to secure the cut sample of dimensions $150 \times 100 \mathrm{~mm}^{2}$ over a $125 \times 75 \mathrm{~mm}^{2}$ hole. 


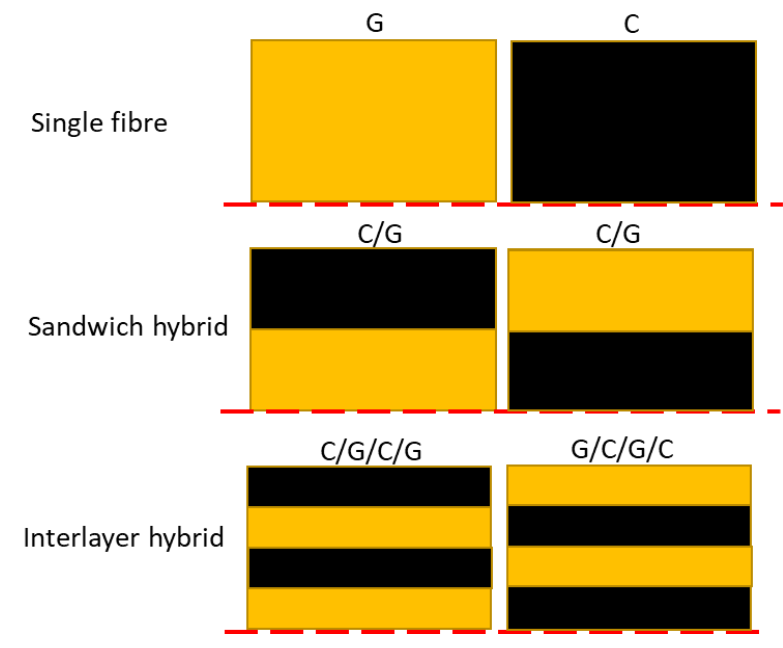

Fig. 1 Schematic and names of the investigated samples

Table 1 Stacking sequence for different cases

\begin{tabular}{cccc}
\hline N. & Name & Stacking sequence & $\begin{array}{c}\text { Thickness } \\
\mathrm{mm}\end{array}$ \\
\hline 1 & $\mathrm{C}$ & $([(0 / 90)( \pm 45)] 4 \mathrm{c}) \mathrm{s}$ & 4 \\
2 & $\mathrm{G}$ & $([(0 / 90)( \pm 45)] 4 \mathrm{~g}) \mathrm{s}$ & 4 \\
3 & $\mathrm{C} / \mathrm{G}$ & $([(0 / 90)( \pm 45)] 2 \mathrm{c} /[(0 / 90)( \pm 45)] 2 \mathrm{~g}) \mathrm{s}$ & 4 \\
4 & $\mathrm{G} / \mathrm{C}$ & $([(0 / 90)( \pm 45)] 2 \mathrm{~g} /[(0 / 90)( \pm 45)] 2 \mathrm{c}) \mathrm{s}$ & 4 \\
5 & $\mathrm{C} / \mathrm{G} / \mathrm{C} / \mathrm{G}$ & $([(0 / 90)( \pm 45)] \mathrm{c} /[(0 / 90)( \pm 45)] \mathrm{g} /$ & 4 \\
& & $[(0 / 90)( \pm 45)] \mathrm{c} /[(0 / 90)( \pm 45)] \mathrm{g}) \mathrm{s}$ & \\
6 & $\mathrm{G} / \mathrm{C} / \mathrm{G} / \mathrm{C}$ & $([(0 / 90)( \pm 45)] \mathrm{g} /[(0 / 90)( \pm 45)] \mathrm{c} /$ & 4 \\
& & $[(0 / 90)( \pm 45)] \mathrm{g} /[(0 / 90)( \pm 45)] \mathrm{c}) \mathrm{s}$ & \\
\hline
\end{tabular}

The test samples were accurately centered and then clamped before raising the impactor to the desired height level.

The gravitational potential energy equation (Energy $=m g h$, where notations $m, g$ and $h$ have their usual meanings of Impactor's mass, acceleration due to gravity and drop height, respectively) was used to calculate the height of the impactor. In order to introduce a reasonable level of damage, a value of $26 \mathrm{~J}$ was assumed.

The rubber tipped toggle clamps were used in such a way that there is no lateral movement in the test sample pieces. A load cell consisted of strain gauges and was positioned underneath the clamped down samples. Strainsmart ${ }^{\circledR}$ software was used to process the signal received from the gauges used.

The signal was received at $10 \mathrm{kHz}$. Fig. 2-d shows a $12.7 \mathrm{~mm}$ ball bearing hemispherical tip impactor. This hemispherical shape of the tip prevents causing any puncturing to the sample and hence avoiding additional damage in the sample. 


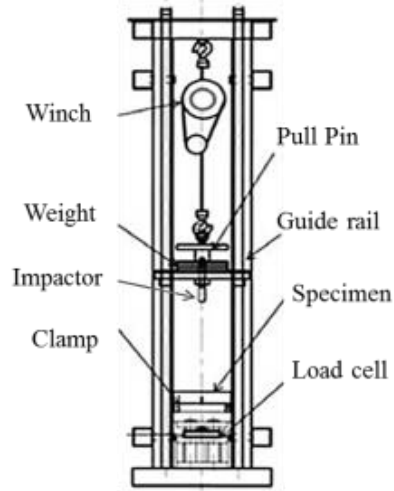

$\mathbf{a}$

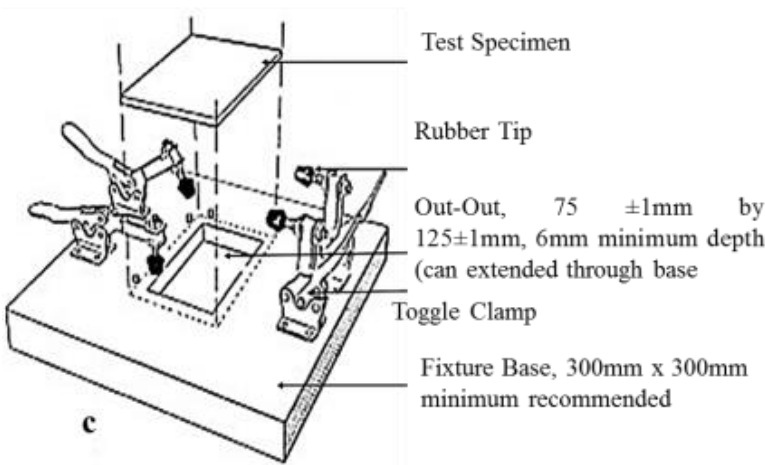

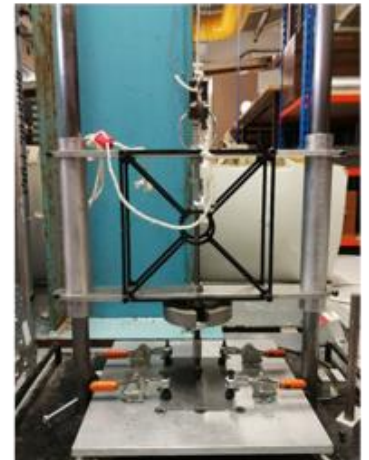

b

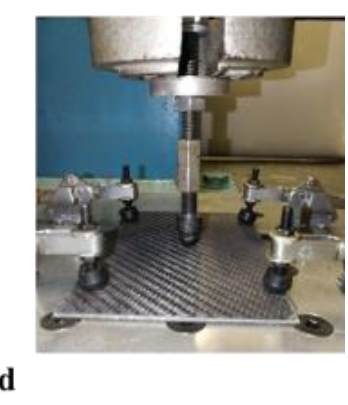

Fig. 2 a) Diagram of a low-velocity test rig, b) Low-velocity test rig (impact tower), d) Clamped sample and impactor, and c) ASTM standard clamp and test set up

Ten measurements for the mass of the impactor were taken and their mean for the total mass found to be $2.82 \mathrm{~kg}$. At each energy level chosen, at least three repeats were done for each configuration reported in the manuscript. The results showed a good repeatability.

To calculate the energy losses in the impactor, equation 1 was used. It was noted that the material absorbed most of the energy. It was also assumed that other energy losses are very minimal and negligible.

$$
E_{1}=\frac{1}{2} m\left(v^{2}-v^{\prime 2}\right)
$$

\section{RESULTS AND DisCUSSIONS}

\subsection{Load-displacement results}

A typical load-displacement diagram for investigated $\mathrm{C}$ samples is shown in Fig. 3. Initially, there is a linear region in the load-displacement which is related to the elastic region in the early stage of the loading process. When the load level reaches a critical load level, the damage (delamination) initiates. After the initiation of damage, there is an 
unstable propagation of the delamination, which is distinguishable from the load drops. The specimens are still integral, and the displacement goes to zero after the impact.

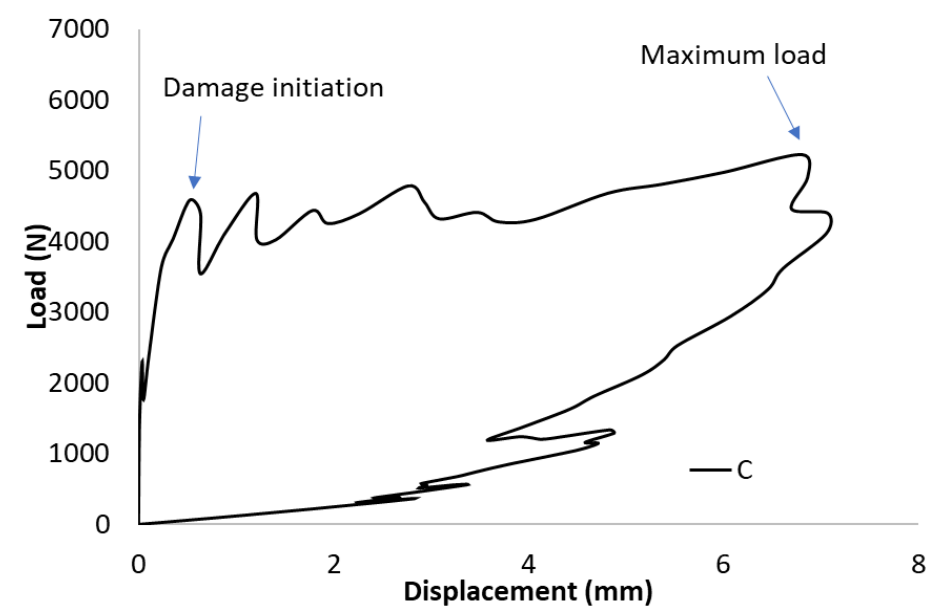

Fig. 3 Load-displacement graph for a typical C impacted at 26J

Fig. 4 shows the load-displacement curves for the impacted samples with different stacking sequences. Considering the shape of the curves, all the samples demonstrate a linear behavior in the early stages of the loading process as an elastic response. This is followed by a drop in the contact force owing to the damage caused by the impact. The main quantitative areas for analysis on these graphs are the critical load at damage initiation, the initial load drop, the maximum contact force, the maximum displacement and the absorbed energy. The

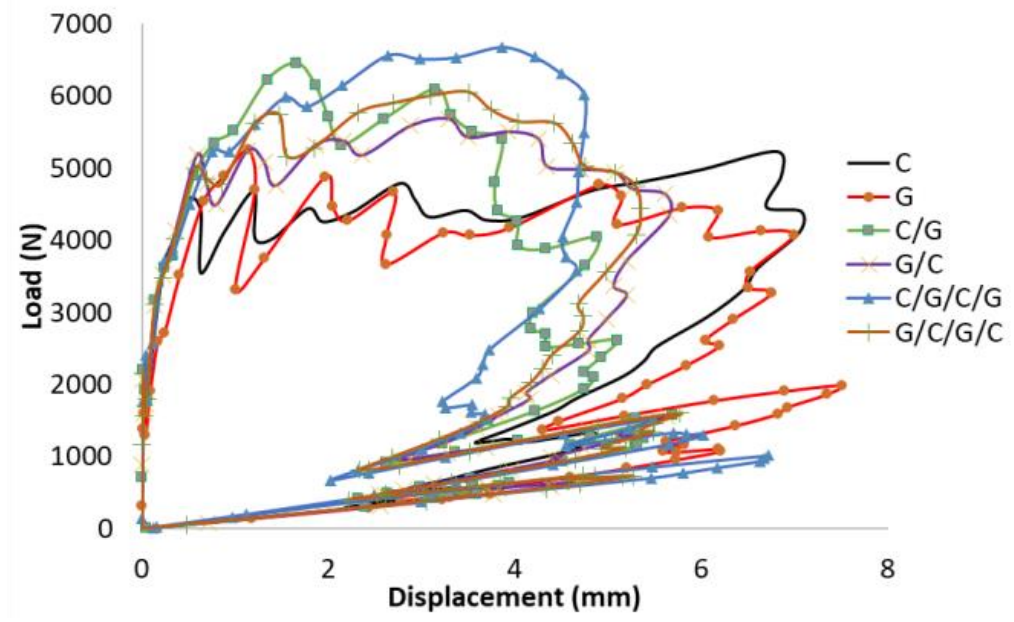

Fig. 4 Comparison of the load-displacement graphs for the investigated samples impacted at $26 \mathrm{~J}$ 
absorbed energy is calculated using Equation 1. As can be seen from Figs. 5 and 6, the critical load for initiation of delamination was found to be slightly higher for the samples with outer layer carbon fiber. However, the hybrid laminates had smaller load drops, which are indicating a more gradual occurrence of damage. In addition, smaller deflection, and higher maximum load compared to the single fiber laminates. The carbon outside interlayer hybrid laminate $(\mathrm{C} / \mathrm{G} / \mathrm{C} / \mathrm{G})$ showed the highest maximum load, while $\mathrm{C}$ laminate had the highest absorbed energy. The results are showing the significant dependence of the impact performance on hybridization and stacking sequence.

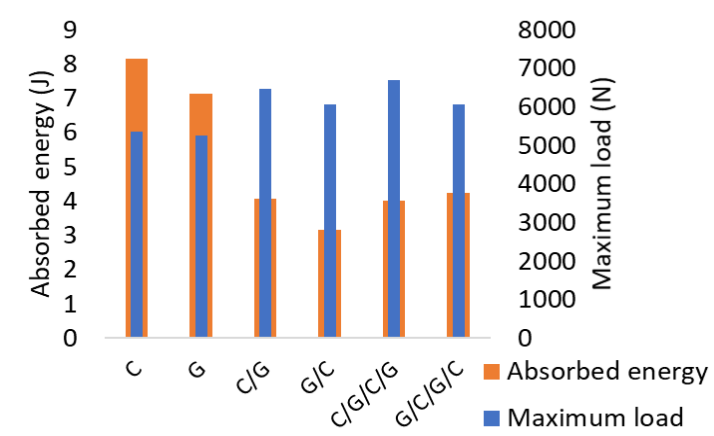

Fig. 5 Comparison of the absorbed energy and maximum load for the investigated samples subjected to $26 \mathrm{~J}$

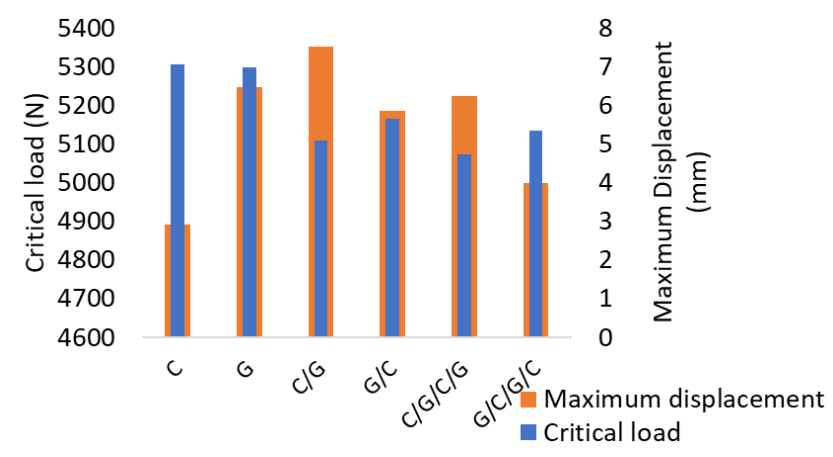

Fig. 6 Comparison of the critical load and maximum displacement for the investigated samples subjected to $26 \mathrm{~J}$

\subsection{Damage Analysis}

The differences in the mechanical properties of the investigated composites are attributed to the impact induced damage mechanisms. Fig. 7 shows the impacted and back side of the investigated samples subjected to $26 \mathrm{~J}$ impact energy. For the $\mathrm{C}, \mathrm{C} / \mathrm{G}$ and $\mathrm{C} / \mathrm{G} / \mathrm{C} / \mathrm{G}$ laminates, there are visible dents on the impacted side, and some fiber fracture and delamination on the back face; however, due to the opaque nature of the carbon prepregs, the damage is not easily observable by the naked eye. Despite this fact, the visible damage on the $\mathrm{C}$ sample looks bigger than the $\mathrm{C} / \mathrm{G}$ and $\mathrm{C} / \mathrm{G} / \mathrm{C} / \mathrm{G}$ laminates. For 
the $\mathrm{G}, \mathrm{G} / \mathrm{C}$ and $\mathrm{G} / \mathrm{C} / \mathrm{G} / \mathrm{C}$ due to the translucent nature of the glass the induced damage can be observed easier. The $\mathrm{G}$ sample has a similar size and pattern of delamination on both impacted and non-impacted faces; however, delamination damage is much larger in the impacted side of the G/C/G/C sample compared to the non-impacted side. Damage and delamination between the dissimilar interfaces, i.e. the carbon/glass interfaces are visible for the $\mathrm{G} / \mathrm{C}$ sample. Overall, the visible damage in the $\mathrm{G}$ composite is greater than the other configurations and the $\mathrm{C} / \mathrm{G} / \mathrm{C} / \mathrm{G}$ and $\mathrm{C} / \mathrm{G}$ configurations have the lowest visible damage size. This is in accordance with the better impact response of these laminates compared with the other laminates.

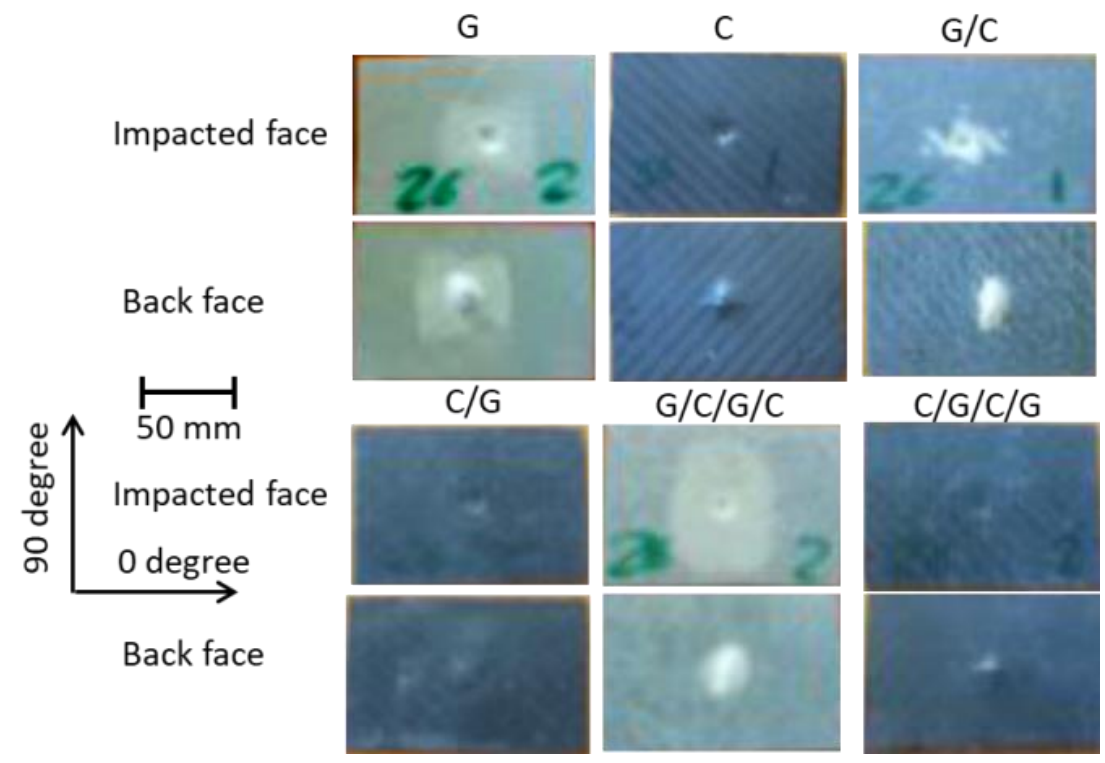

Fig. 7 Impacted surface and back surface (non-impacted side) view of the investigated samples subjected to $26 \mathrm{~J}$

\section{CONCLUSIONS}

This paper studies the effect of stacking sequence on mechanical response and failure patterns of glass/epoxy hybrid composites under low velocity impact. A comprehensive set of drop test impact tests were done on single fiber laminate and 2 different types of interlayer woven glass-carbon/epoxy hybrid laminates. It was found that using carbon fiber as top and bottom layers for composites ( $\mathrm{C} / \mathrm{G}$ and $\mathrm{C} / \mathrm{G} / \mathrm{C} / \mathrm{G}$ laminates) helps to increase the maximum load, reduce the damage size and maximum displacement. In addition the hybrid laminates absorbed less impact energy compared to the single fiber laminates. The translucent nature of the glass prepregs allowed a better visual induced damage assessment for the laminates with glass as their layer (i.e. G, G/C and G/C/G/C) compared to the laminates with carbon as the outer layer. The paper concludes that a hybrid composite would help to improve impact performance if it is well designed. 


\section{REFERENCES}

1. Gay, D., 2014, Composite materials: design and applications, CRC press.

2. Mangalgiri, P.D., 1999, Composite materials for aerospace applications, Bulletin of Materials Science, 22(3), pp. 657-664.

3. Dutton, S., Kelly, D., Baker, A., 2004, Composite materials for aircraft structures. American Institute of Aeronautics and Astronautics.

4. Elmarakbi, A., 2013, Advanced composite materials for automotive applications: Structural integrity and crashworthiness, John Wiley \& Sons.

5. Mangino, E., Carruthers, J., Pitarresi, G., 2007, The future use of structural composite materials in the automotive industry, International Journal of Vehicle Design, 44(3-4), 211-232.

6. Minak, G., Brugo, T., Fragassa, C., Pavlovic, A., 2019, Structural design and manufacturing of a cruiser class solar vehicle, Journal of Visual Experiments, 143, e58525, doi:10.3791/58525.

7. Galanis, K., Hull construction with composite materials for ships over $100 \mathrm{~m}$ in length, Diss. Massachusetts Institute of Technology, 2002

8. Fragassa, C., 2017, Marine applications of natural fibre-reinforced composites: a manufacturing case study, Advances in Application of Industrial Biomaterials, Springer, Cham, CH. doi: 10.1007/978-3-319-627670_2: pp 21-47

9. Sun, L. N., Deng, Z., 2012, The carbon fiber composite materials application in sports equipment. In Advanced Materials Research (Vol. 341, pp. 173-176). Trans Tech Publications Ltd.

10. Salernitano, E., Migliaresi, C., 2003, Composite materials for biomedical applications: a review, Journal of Applied Biomaterials and Biomechanics, 1(1), pp. 3-18.

11. Safri, S.N.A., Sultan, M.T.H., Yidris, N., Mustapha, F., 2014, Low velocity and high velocity impact test on composite materials - A review, The International Journal of Engineering and Science (IJES), 3, pp. 50-60.

12. Laffan, M.J., Pinho, S.T., Robinson, P., McMillan, A.J., 2012, Translaminar fracture toughness testing of composites: A review, Polymer testing, 31(3), pp. 481-489.

13. Swolfs, Y., Gorbatikh, L., Verpoest, I., 2014, Fibre hybridisation in polymer composites: A review, Composite Part A Applied Science and Manufacturing, 67, pp. 181-200.

14. Czél, G., Wisnom, M.R., 2013, Demonstration of pseudo-ductility in high performance glass-epoxy composites by hybridisation with thin-ply carbon prepreg, Composite Part A: Applied Science and Manufacturing, 52, pp. 23-30.

15. Short, D., Summerscales, J., 1979, Hybrids-a review: Part 1. Techniques, design and construction, Composites, 10(4), pp. 215-222.

16. Curtis, P.T., Browne, M., 1994, Cost-effective high performance composites, Composites, 25, pp. 273-280.

17. Fotouhi, M., Suwarta, P., Jalalvand, M., Czel, G., Wisnom, M.R., 2016, Detection of fibre fracture and ply fragmentation in thin-ply UD carbon/glass hybrid laminates using acoustic emission, Composites Part A: Applied Science and Manufacturing, 86, pp. 66-76.

18. Jalalvand, M., Fotouhi, M., Wisnom, M.R., 2017, Orientation-dispersed pseudo-ductile quasi-isotropic hybrid composites - A new hybridisation concept to avoid free-edge delamination, Composite Science and Technology, 153, pp. 232-240.

19. Jalalvand, M., Idarraga, G., Fotouhi, M., Meza, J., Wisnom, M.R., 2019, Achieving gradual failure in hybrid composite laminates-progressing from tension to bending, Proc. $22^{\text {nd }}$ International Conference on Composites Materials ICCM22 2019, Melbourne, Australia.

20. Saravanakumar, K., Sai Lakshminarayanan, B., Arumugam, V., Santulli, C., Pavlovic, A., Fragassa, C., 2019, Quasi-static indentation behavior of GFRP with milled glass fiber filler monitored by acoustic emission, Facta Universitatis-Series Mechanical Engineering, 17(3), pp. 425-443.

21. Suwarta, P., Czél, G., Fotouhi, M., Rycerz, J., Wisnom, M.R., 2018, Pseudo-ductility of unidirectional thin ply hybrid composites in longitudinal compression, Proc. $33^{\text {rd }}$ the American Society for Composites ASC Annual Technical Conference, 2018, Seattle, USA.

22. Fotouhi, M., Jalalvand, M., Prato, A., Wisnom, M.R., 2018, Thin ply carbon/ glass hybrid laminates to activate new damage mechanisms under indentation, Proc. $18^{\text {th }}$ European Conference on Composite Materials ECCM 18, 2018, Athens, Greece.

23. Zivkovic, I., Pavlovic, A., Fragassa, C., Brugo T.M., 2017, Influence of moisture absorption on the impact properties of flax, basalt and hybrid flax/ basalt fiber reinforced green composites, Composites Part B: Engineering, 111, pp 148-164.

24. Dong, C.S., Davies, I.J., 2015, Flexural strength of bidirectional hybrid epoxy composites reinforced by E glass and T700S carbon fibres, Composite Part B: Engineering, 72, pp. 65-71. 
25. Wang, C.J., Jang, B.Z., Panus, J., Valaire, B.T., 1991, Impact behavior of hybrid fibre and hybrid matrix composites, Journal of reinforced plastics and composites, 10, pp. 356-78.

26. Kowsika, M., Mantena, P.R., 1999, Static and low-velocity impact response of pulthouded hybrid glassgraphitelepoxy composite beams, Journal of Thermoplastic Composite Materials, 12, pp. 121-132.

27. Fragassa, C., Pavlovic, A., Santulli, C., 2018, Mechanical and impact characterisation of flax and basalt fibre bio-vinylester composites and their hybrids, Composites Part B: Engineering, 137, pp. 247-259.

28. Askaripour, K., Fadaee, M.J., 2019, Diagnosis of delaminated composites using post-processed strain measurements under impact loading, International Journal of Engineering, Transactions A: Basic, 32, pp. 54-61.

29. El-Wazery, M., 2019, Mechanical characterization of glass-basalt-carbon/polyester hybrid composites, International Journal of Engineering, Transactions A: Basic, 31, pp. 1139-1145.

30. Fotouhi, S., Clamp, J., Bolouri, A., Pozegic, T.R., Fotouhi, M., 2019, Investigating polyethersulfone interleaved Glass/Carbon hybrid composite under impact and its comparison with GLARE, Composite Structures, 226, pp. 111268-77.

31. Diao, H., Bismarck, A., Robinson, P., Wisnom, M.R., 2014, Production of continuous intermingled CF/GF hybrid composite via fibre tow spreading technology, Proc. $6^{\text {th }}$ European Conference on Composite Materials ECCM 16, 2014, Seville, Spain.

32. Yu, H., Longana, M.L., Jalalvand, M., Wisnom, M.R., Potter, K.D., 2015, Pseudo-ductility in intermingled carbon/glass hybrid composites with highly aligned discontinuous fibres, Composite Part A: Applied Science and Manufacturing, 73, pp. 35-44.

33. Czél, G., Jalalvand, M., Wisnom, M.R., 2016, Design and characterisation of advanced pseudo-ductile unidirectional thin-ply carbon/epoxy-glass/epoxy hybrid composites, Composite Structures, 143, pp. 362-370.

34. Swolfs, Y., Crauwels, L., Breda, E., Gorbatikh, L., Hine, P., Ward, I., Ignaas, V., 2014, Tensile behaviour of intralayer hybrid composites of carbon fibre and self-reinforced polypropylene, Composite Part A: Applied Science and Manufacturing, 59, pp. 78-84.

35. ASTM D7136-Standard Test Method for Measuring the Damage Resistance of a Fiber-Reinforced Polymer Matrix Composite to a Drop-Weight Impact Event, 2005. 